\section{Somatic response as a function of no signal, random signal, or signaled shock with variable or constant durations of shock}

\author{
J. MEZINSKIS, J. GLINER, and K. SHEMBERG \\ Bowling Green State University, Bowling Green, Ohio 43402
}

Gastric ulcertation was studied in rats exposed to predictable shock (signaled) or unpredictable shock (either random signals and shock or shock alone), where these shock programs were delivered under conditions of either fixed or variable shock durations. Results were compatible with previous work, suggesting that predictable shocks are less ulcerogenic than unpredictable ones. In addition, the present study suggests that this relationship obtains when unpredictability is defined as signals and shocks at random or as shocks with no signals. Also, predictable shock was less ulcerogenic than unpredictable shock irrespective of when the shock durations were fixed or variable.
Recent research indicates that animals exposed to certain programs of unpredictable electric shocks exhibit greater gastric pathology (i.e., stomach ulceration) than do animals exposed to the same amount and pattern of predictable shocks (Seligman, 1968, 1970; Weiss, 1970). In these studies, unpredictable shocks were defined as the presentation of shocks with signals at random. A series of pilot studies carried out in our laboratory has suggested that these previously observed relationships between predictable-unpredictable shock and stomach ulceration may not obtain if unpredictable shock is defined as unsignaled shocks alone rather than as shocks and signals at random. It seemed possible that the few pairings of shocks and signals which can occur in a random shock-signal program may add some condition which is highly aversive to the organism and which may be an important factor in producing differences in ulceration between signaled and randomly signaled shock conditions. One purpose of the present research was to explore this possibility more carefully. In addition, the parameter of constant vs variable shock durations was studied.

Up to now research on ulceration within the predictable-unpredictable paradigm has focused primarily upon presenting animals with either predictable or unpredictable shocks of one given duration. Preliminary work in our laboratory has suggested that in signaled shock conditions where signals preceded shocks of a constant duration, animals were less severely affected than were animals receiving the same total amount of signaled shock but where durations of individual shocks varied. Thus a second purpose of this experiment was to investigate the possibility that unsystematic associative factor to this
Model 111-C, controlled shock and signal durations. Signals were provided by a 4 -W lamp blinking every $1 / 2$ sec. This light was mounted in the ceiling of the sound-attenuating chamber. It was easily discriminable as a signal, since it provided the only light in the chamber. A dual LVE tape programmer controlled signal onset and shock onset.

\section{PROCEDURE}

Animals were assigned to one of six groups ( $N=12$ per group): signaled shock, fixed durations; signaled shock, variable durations; unsignaled shock, fixed durations; unsignaled shock, variable durations, light and shock at random, fixed durations; light and shock at random variable durations. Two Ss were run each day, both in the same group. Groups were ordered so that each experimental condition occurred once every 6 days. All Ss were food deprived $24 \mathrm{~h}$ preceding the experimental-session. The animals were then placed in the restraining cages for $1 \mathrm{~h}$ of habituation followed by a 19 -h stress period. During these $19 \mathrm{~h}$, a 3.5-mA shock occurred randomly every $30-90 \mathrm{sec}$, with an average of one shock every 60 sec. For signaled shock groups, the signal began $10 \mathrm{sec}$ before the onset of shock and terminated at the onset of shock. For unsignaled shock groups, the blinking light did not occur during the experimental session. Groups receiving light and shocks at random received a 10 -sec blinking light randomly every $30-90 \mathrm{sec}$, with an average of one light every $60 \mathrm{sec}$. Animals in the constant shock-duration conditions always received 2-sec shocks. Animals in the variable shock-duration conditions received shock durations of $.5, .87,1.50,2.61$, and $4.52 \mathrm{sec}$ (an average of $2 \mathrm{sec}$ duration). These durations were presented in random order for 40 shocks, at which time the 40 -shock sequence repeated itself. This rotation continued throughout the 19-h experimental session. Although in some conditions in the experiment individual shock durations varied, all Ss received the same total amount of shock over the 19-h session.
Instruments shock sources, each shock source serving one cage. Hunter timers,

Table 1

Percentage of Ss Ulcerating Per Group, Median and Mean Number of Ulcers Per Group, and Standard Deviations

\begin{tabular}{lcccc}
\hline Groups & $\begin{array}{c}\text { Percentage } \\
\text { of Ss } \\
\text { Ulcerating }\end{array}$ & $\begin{array}{c}\text { Nedian } \\
\text { Number } \\
\text { of Ulcers }\end{array}$ & $\begin{array}{c}\text { Mean } \\
\text { Number } \\
\text { of Ulcers }\end{array}$ & SD \\
\hline Fixed Shock Duration & & & & \\
$\quad$ Signaled & 67 & 2 & 1.83 & 1.59 \\
$\quad$ Unsignaled & 100 & 3 & 3.83 & 2.76 \\
$\quad$ Random Signal & 92 & 2 & 2.25 & 1.66 \\
Variable Shock Duration & 58 & 2 & & 1.67 \\
$\quad$ Signaled & 100 & 2 & 3.58 & 1.61 \\
Unsignaled & 92 & 3 & 4.67 & 2.68 \\
$\quad$ Random Signal & & & & 5.33 \\
\hline
\end{tabular}


Following the experimental session, Ss were returned to their home cages for $6 \mathrm{~h}$ with water ad lib but no food. At the end of $6 \mathrm{~h}$, Ss were sacrificed. Stomachs were removed, opened along the greater curvature, and pinned to cork boards for examination. A judge, experienced in gastric pathology but naive with respect to treatment conditions, counted the number of glandular stomach lesions per $S$. In addition to ulceration measures, Ss were weighed prior to deprivation, prior to entering the experimental apparatus, immediately after the $19-\mathrm{h}$ session and immediately prior to being sacrificed.

RESULTS AND DISCUSSION

Table 1 shows the percentage of Ss developing ulcers in each group, the median and mean number of ulcers per group, and the standard deviations. A chi-square test performed on the frequency of Ss developing ulcers for the predictability factor collapsed across duration demonstrated that significantly fewer $S s$ in the signal shock groups developed ulcers when compared to the two unpredictable shock groups $\left(x^{2}=14.37, \quad \mathrm{df}=2\right.$, $\mathrm{p}<.01)$. There were no differences between the two unpredictable shock groups, nor were there any differences due to fixed vs variable duration in terms of frequency of ulceration. A two-factor analysis of variance (Predictability by Shock Duration) also revealed that the signal shock groups had significantly fewer ulcers than did the unpredictable shock groups $(F=3.20, d f=2 / 66, p<.05)$. There were no differences between groups in terms of fixed vs variable durations of shock $(\mathrm{F}<1, \mathrm{df}=1 / 66)$. Analysis of weight loss data failed to reveal any systematic differences among the groups.

The results of the present study are consistent with the Weiss (1970) work in that animals receiving fixed durations of signaled shock were less affected in terms of gastric ulceration than were rats receiving fixed durations of shocks and signals at random. Furthermore, it appears that there are no differences in aversiveness between shocks and signals at random and unsignaled shock, at least as measured by the development of gastric ulcers and within the current experimental paradigm. Also, results suggest that predictable shock is less aversive than unpredictable shock even under conditions where individual shock durations are variable. Thus it appears that the previously observed relationship between predictable shock, unpredictable shock, and gastric ulceration is a generally reliable one and one which is independent of the other parameters manipulated in the current study.

\section{REFERENCES}

SELIGMAN, MI. E. P. Chronic fear produced by unpredictable shock. Journal of Comparative \& Physiological Psychology, 1968, 66, 402-411.

SELIGMAN, II. E. P. Chronic fear and ulcers in rats as a function of the unpredictability of safety. Joumal of Comparative \& Physiological Psychology, $1970,73,193-201$.

WEISS, J. M. Somatic effects of predictable and unpredictable shock. Psychosomatic Medicine, 1970, 32, 397-408. 